\title{
Synchronous Occurrence of Hodgkin's Lymphoma and Lung Cancer
}

Erdem R*, Aykas F, Gocer M, Ozen IN, Aslan V, Celik M, Cetin G and Kurtoglu E

Department of Internal Medicine, Antalya Training and Research Hospital, Turkey

*Corresponding author: Ramazan Erdem, Department of Internal Medicine, Antalya Training and Research Hospital, Division of Hematology, Varlık Mh Kazım Karabekir Cd. 07100, Antalya, Turkey

Received: February 01, 2021; Accepted: February 26, 2021; Published: March 05, 2021

\begin{abstract}
Hodgkin lymphoma is an uncommon neoplasm that characterized young age of onset, Hodgkin and Reed-Sternberg (HRS) cells derived from B-lymphocytes and a high cure rate, even when the patient presents with advanced metastatic spread. Lung cancer is the most common cancer worldwide and is still responsible for the most cancer deaths. We present an extremely rare case of coexisting Hodgkin lymphoma and lung cancer in a 67-year-old male patient. He initially presented with chest pain. Pet/ct revealed mass in the right lung and lymph nodes in the neck. Biopsy from the premaxillary lymph node was compatible with classical Hodgkin lymphoma. In terms of second primary malignancy, a biopsy was also performed from the mass in the right lung. Pathology showed a pulmonary adenocarcinoma and a right upper lobectomy was then performed. This patient was treated with gemcitabine plus docetaxel for lung cancer. At the end of treatment pet/ct was complete response including lymph nodes in the neck. Therefore, we did not give any treatment for Hodgkin lymphoma. The patient is still being followed up in remission.
\end{abstract}

Keywords: Hodgkin lymphoma; Lung cancer; Synchronous; Cancer therapy

\section{Introduction}

Hodgkin Lymphoma (HL) is a rare B-cell malignant neoplasm involving lymph nodes and the lymphatic system. The disease has a bimodal disease distribution and its incidence has increased in patients in their 20s and over 55 years of age [1]. In 2020, an estimated 8480 people will be diagnosed with HL in the United States and 970 people will die from the disease [2]. HL is divided into two major subgroups, based on morphology and immunophenotype: classic Hodgkin Lymphoma (cHL) and Nodular Lymphocyte-Predominant Hodgkin Lymphoma (NLPHL) [3]. cHL accounts for approximately 90 percent of HL, while NLPHL accounts for the remainder of cases [4]. Pathology is an important means of diagnosis and classification. The treatment of patients with HL is primarily guided by the clinical stage of the disease. Early-stage disease is treated with a combination of chemotherapy plus radiation therapy, while advanced stage disease receives a longer course of chemotherapy without radiation therapy [5].

Lung cancer is the most common cancer and leading cause of death in both men and women worldwide. GLOBOCAN estimated 2.09 million new cases and 1.76 million deaths worldwide in 2018 [6]. Among the common subtypes of lung cancer, Non-Small Cell Lung Cancer (NSCLC) accounts for $80-85 \%$ of all cases and small cell lung cancer accounts for the remaining 15-20\%. Among non-small cell variants, adenocarcinoma is the most common type in contemporary series, accounting for approximately one-half of lung cancer cases [7]. Surgery, RT, chemotherapy and molecular targeted therapies are the modalities most commonly used to treat patients with NSCLC. They can be used either alone or in combination depending on the disease status [8].
Multiple studies have reported an increased risk for lung cancer as secondary neoplasms after treatment for HL patients [9-11]. However, we could not find synchronous lung cancer and Hodgkin lymphoma in the literature. The aim of this study is to present the first case of incidental discovery Hodgkin lymphoma and lung cancer.

\section{Case Presentation}

A 67-year-old man was admitted to our hospital on June 2019 due to chest pain and clinically significant weight loss that had been apparent since May 2019. Since the symptoms first occurred, the patient had experienced no night sweats or fever. The patient's medical history included heavy smoker and appendectomy. On physical examination, there was no pathology except prolonged expiration. Laboratory findings were within normal limits except for mild anemia. Firstly, plain chest radiography was obtained, which revealed a mass in the right lung. Pet/ct was performed for further evaluation, which revealed a right lung upper lobe posterior mass measuring $65 \times 58 \mathrm{~mm}$ (SUV max:16,7) and suspected in terms of metastasis in the neck, lymph nodes with the largest size of $14 \times 9 \mathrm{~mm}$ (SUV max:15) was detected at left level $2 \mathrm{~b}$ and premaxillary. Biopsy from the premaxillary lymph node was compatible with classical Hodgkin lymphoma. There was no bone marrow involvement in pet/ ct. According to the Ann Arbor System, Hodgkin lymphoma was classified as stage IIB.

In terms of second primary malignancy, a biopsy was also performed from the mass in the right lung. The frozen section showed a pulmonary adenocarcinoma. A right upper lobectomy was then performed confirming the diagnosis. Histopathological findings were consistent with pulmonary adenocarcinoma with TTF-1 expression. This tumor was classified PT4N0M0. The patient was primarily referred 
to oncology and he was treated for pulmonary adenocarcinoma by four cycles gemcitabine plus docetaxel (gemcitabine on day 1 and docetaxel on day 1 and 8, every 21 days). At the end of treatment pet/ct was complete response including lymph nodes in the neck. Therefore, we did not give any treatment for Hodgkin lymphoma. The patient is still being followed up in remission.

\section{Discussion}

HL are lymphoid neoplasms that characterized HRS cells. As the majority of patients with Hodgkin lymphoma achieve long-term survival free of HL, late complications of the treatment have emerged as a competing cause of death and morbidity. Long-term survivors are at risk for developing second malignancies. Solid tumors account for the most second cancers in HL survivors, with lung, breast, stomach, esophagus, colon/rectum, cervix, mouth and pharynx, and melanoma. Radiotherapy and alkylating chemotherapy can substantially increase the risk of solid malignancy, in particular risks of lung cancer, stomach, and pancreatic cancer [12]. Our patient was not treated with radiotherapy and chemotherapy. Therefore, we speculated that HL and lung cancer occurred incidentally. The relationship between the synchronous development of these two tumors remains unclear. Additional cases, therefore, need to be investigated in order to further clarify the key diagnostic and therapeutic characteristics of synchronous neoplasms.

Multiple primary cancers are defined as the occurrence of two or more primary cancers in the same patient, either simultaneously or sequentially [13]. Although synchronous lung cancer and nonHodgkin lymphoma have been reported in the literature [14-20], we could not find any reporting synchronous Hodgkin lymphoma and lung cancer. To our best knowledge, this is the first case in the literature.

Previous studies have reported the simultaneous occurrence of HL and hematological malignancies such as chronic lymphocytic leukemia, peripheral T-cell lymphoma, or diffuse large B-cell lymphoma [21-25]. Also, Hodgkin lymphoma can be seen as synchronous or metachronous with solid tumors such as testicular germ cell neoplasm, laryngeal squamous cell carcinoma, colon carcinoma, gastric adenocarcinoma and pleomorphic adenoma [2633].

Due to the rarity of coexisting malignancies such as this, diagnosis and treatment are the most challenging problem. In the absence of guidelines for the management of such diseases, the therapeutic management should be determined according to the physician's experience. The biological behavior of the disease, patient performance status, and the estimated morbidity related to chemoradiotherapy should be taken into account. The case must be managed using a multidisciplinary approach.

In the present case report, the patient received chemotherapy for lung cancer alone. After lung cancer treatment, the pet/ct was in complete response. Gemcitabine, which is used for lung cancer treatment, is also used in the treatment of Hodgkin lymphoma, especially in salvage therapy. We think that lymph nodes in the neck may have responded to this treatment. Therefore, we preferred wait and watch for HL treatment. The patient was still in remission and in good health 12 months later. In conclusion, biopsy of the suspicious lymph nodes should be performed to confirm malignancy metastasizing from lung cancer or other lesions. Similarly, in HL patients with suspicious lung mass, a biopsy should be performed to exclude lung cancer.

\section{References}

1. Ansell SM. Hodgkin Lymphoma: Diagnosis and Treatment. Mayo Clinic proceedings. 2015; 90: 1574-1583.

2. Siegel RL, Miller KD. Cancer statistics, 2020. 2020; 70: 7-30.

3. Piris MA, Medeiros LJ, Chang KC. Hodgkin lymphoma: a review of pathological features and recent advances in pathogenesis. Pathology. 2020; 52: 154-165.

4. Siegel RL, Miller KD, Jemal A. Cancer Statistics, 2017. CA: a cancer journal for clinicians. 2017; 67: 7-30.

5. Ansell SM. Hodgkin lymphoma: 2018 update on diagnosis, risk-stratification, and management. American journal of hematology. 2018; 93: 704-715.

6. Bray F, Ferlay J, Soerjomataram I, Siegel RL, Torre LA, Jemal A. Global cancer statistics 2018: GLOBOCAN estimates of incidence and mortality worldwide for 36 cancers in 185 countries. CA: a cancer journal for clinicians. 2018; 68: 394-424.

7. Peters S, Adjei AA, Gridelli C, Reck M, Kerr K, Felip E. Metastatic Non-SmallCell Lung Cancer (NSCLC): ESMO Clinical Practice Guidelines for diagnosis, treatment and follow-up. Annals of oncology: official journal of the European Society for Medical Oncology. 2012; 23: vii56-64.

8. Hirsch FR, Scagliotti GV, Mulshine JL, Kwon R, Curran WJ, Wu YL, et al. Lung cancer: current therapies and new targeted treatments. Lancet (London, England). 2017; 389: 299-311.

9. Sud A, Thomsen H, Sundquist K, Houlston RS, Hemminki K. Risk of Second Cancer in Hodgkin Lymphoma Survivors and Influence of Family History. Journal of clinical oncology: official journal of the American Society of Clinical Oncology. 2017; 35: 1584-1590.

10. Almagro-Casado E, Sanchez A, Cantos B, Salas C, Perez-Callejo D, Provencio M. Lung cancer and other second neoplasms after treatment of Hodgkin lymphoma. Clinical \& translational oncology: official publication of the Federation of Spanish Oncology Societies and of the National Cancer Institute of Mexico. 2016; 18: 99-106.

11. Lorigan P, Radford J, Howell A, Thatcher N. Lung cancer after treatment for Hodgkin's lymphoma: a systematic review. The Lancet Oncology. 2005; 6: 773-779.

12. van Leeuwen FE, $\mathrm{Ng} \mathrm{AK}$. Long-term risk of second malignancy and cardiovascular disease after Hodgkin lymphoma treatment. Hematology American Society of Hematology Education Program. 2016; 2016: 323-330.

13. Park SL, Caberto CP, Lin Y, Goodloe RJ, Dumitrescu L, Love SA, et al. Association of cancer susceptibility variants with risk of multiple primary cancers: The population architecture using genomics and epidemiology study. Cancer epidemiology, biomarkers \& prevention: a publication of the American Association for Cancer Research, cosponsored by the American Society of Preventive Oncology. 2014; 23: 2568-2578.

14. Pascua J, Robaina G, Di Tullio F, Samudio M, Mendez J, Auvieux R, et al. [Synchronous pulmonary adenocarcinoma and primary lymphoma of lung mucosa-associated lymphoid tissue]. Medicina. 2019; 79: 208-211.

15. Li J, Zhou C, Liu W, Sun X, Meng X. Synchronous diffuse large B-cell lymphoma of the stomach and small cell lung carcinoma: A case report. Medicine. 2017; 96: e8873.

16. Samuel G, Simoff M, Chaabaan S, Diaz-Mendoza J. Synchronic Diagnosis of Non-Hodgkin Lymphoma and Lung Adenocarcinoma via EBUS-guided TBNA. Journal of bronchology \& interventional pulmonology. 2018; 25 . e41-e42.

17. Jung CY, Kwon KY. A Case of Synchronous Lung Adenocarcinoma and Extranodal Marginal Zone B-Cell Lymphoma of Mucosa-Associated Lymphoid Tissue (MALT) Type. Tuberculosis and respiratory diseases. 2012; 73: 61-66. 
18. Hatzibougias D, Bobos M, Karayannopoulou G, Karkavelas G Karapanagiotidis GT, Foroulis $\mathrm{CN}$, et al. A rare tumoral combination, synchronous lung adenocarcinoma and mantle cell lymphoma of the pleura. World journal of surgical oncology. 2008; 6: 137.

19. Satoh T, Arai E, Kayano H, Sakaguchi H, Takahashi N, Tsukasaki K, et al. Pulmonary intravascular large B-cell lymphoma accompanying synchronous primary pulmonary adenocarcinoma and benign interstitial lesions. Journal of clinical and experimental hematopathology: JCEH. 2019; 59: 140-144.

20. Aqeel M, Uysal-Biggs N, Fenske TS, Rao N. One Pulmonary Lesion, 2 Synchronous Malignancies. Journal of investigative medicine high impact case reports. 2018; 6: 2324709618785934.

21. Weisenberg E, Anastasi J, Adeyanju M, Variakojis D, Vardiman JW Hodgkin's disease associated with chronic lymphocytic leukemia. Eight additional cases, including two of the nodular lymphocyte predominant type. American journal of clinical pathology. 1995; 103: 479-484.

22. Chan WC, Griem ML, Grozea PN, Freel RJ, Variakojis D. Mycosis fungoides and Hodgkin's disease occurring in the same patient: report of three cases. Cancer. 1979; 44: 1408-1413.

23. Harris NL. The relationship between Hodgkin's disease and non-Hodgkin's lymphoma. Seminars in diagnostic pathology. 1992; 9: 304-310.

24. Adnan E, Nicholas S, Madras R, Ashraf AM. Synchronous Hodgkin's disease and non-Hodgkin's lymphoma. Acta oncologica (Stockholm, Sweden). 1996 35: $755-757$.

25. Goyal G, Nguyen AH, Kendric K, Caponetti GC. Composite lymphoma with diffuse large B-cell lymphoma and classical Hodgkin lymphoma components: A case report and review of the literature. Pathology, research and practice. 2016; 212: 1179-1190.

26. Dexeus FH, Kilbourn R, Chong C, Logothetis CJ, Sella A, Grignon D.
Association of germ cell tumors and Hodgkin's disease. Urology. 1991; 37: 129-134.

27. Joo YH, Jung CK, Sun DI, Kim MS. Synchronous laryngeal squamous cell carcinoma and Hodgkin lymphoma of the head and neck region. Auris, nasus, larynx. 2009; 36: 501-504

28. Demirci U, Buyukberber S, Yilmaz G, Ozturk B, Akyurek N, Yildız R, et al. Coexistence Hodgkin's lymphoma and colonic adenocarcinoma: a case report. Medical Oncology. 2010; 27: 62-64.

29. Quilon JM, Day S, Lasker JC. Synchronous tumors: Hodgkin disease presenting in mesenteric lymph nodes from a right hemicolectomy for colon carcinoma. Southern medical journal. 2004; 97: 1133-1135.

30. Petros JG, Argy O. Hodgkin's disease in the mesenteric lymph nodes in a patient with colon carcinoma. The Mount Sinai journal of medicine, New York. 1990; 57: 368-370

31. Arslan UY, Oksuzoglu B, Onder FO, Irkkan C, Uyeturk U, Gokbayrak N, et al. Concomitant Hodgkin's lymphoma and gastric adenocarcinoma: a rare coincidence. Medical oncology (Northwood, London, England). 2011; 28 : 251-254.

32. Wu H, Wei L, Hao L, Li X, Wang L, Yuan C. Synchronous Hodgkin lymphoma and gastric adenocarcinoma: A rare case report and literature review. Medicine. 2018; 97: e9484.

33. Manganaris A, Patakiouta F, Kiziridou A, Manganaris T. Concurrent primary Hodgkin's lymphoma and recurrent pleomorphic adenoma of the ipsilateral parotid gland: report of a rare case. European archives of otorhino-laryngology: official journal of the European Federation of Oto-RhinoLaryngological Societies (EUFOS): affiliated with the German Society for OtoRhino-Laryngology - Head and Neck Surgery. 2007; 264: 71-74. 